\title{
Arbitraje estatutario en Ecuador: recientes reformas legislativas con errores de bulto
}

\author{
Eduardo Carmigniani* \\ Carla Cepeda Altamirano** \\ Bernarda Muriel Bedoya*** \\ Recibido/Received: 13/09/2021 \\ Aceptado/Accepted: 11/10/2021
}

SumARIO: 1. Introducción. 2. Arbitraje societario en Ecuador. 2.1. Desarrollo histórico. 2.2. Postura de la Superintendencia de Compañías, Valores y Seguros. 3. Formas de incorporación. 3.1. Incorporación en la fundación. 3.2. Incorporación posterior a la fundación. 3.3. Transferencia de acciones. 4. Reformas recientes. 5. Conclusiones.

Resumen: El arbitraje estatutario es un mecanismo para solventar controversias societarias entre los diferentes actores en el desenvolvimiento de una compañía como socios, accionistas, administradores, fiscalizadores, entre otros. En Ecuador, la habilitación legal y constitucional para acudir a arbitraje estatutario ha existido desde hace décadas. Sin embargo, poco o nada se ha empleado esta figura. En nuestro criterio, por falta de difusión. Desde 2019 se promovieron reformas a la Ley de Compañías incluyendo normativa relacionada con esta materia. Creemos que el ánimo del legislador era promover el arbitraje intra-societario. No obstante, los textos aprobados merecen severos reparos

Palabras Clave: arbitraje estatutario (societario), disputas societarias, reformas legales.

\footnotetext{
* Socio de Carmigniani Pérez Abogados. Abogado por la Universidad Católica de Guayaquil. Correo electrónico: ecarmi@cplaw.ec

** Asociada de Carmigniani Pérez Abogados. Abogada por la Universidad San Francisco de Quito. LLM por la Universidad de Stanford. Correo electrónico: ccepeda@cplaw.ec

*** Asociada de Carmigniani Pérez Abogados. Abogada por la Universidad San Francisco de Quito. Correo electrónico: bmuriel@cplaw.ec
} 


\title{
Statutory arbitration in Ecuador: recent legislative amendments with some cardinal mistakes
}

\begin{abstract}
Aвstract: Statutory arbitration is an efficient mechanism to solve disputes arising between shareholders, board members, managers, and the company itself, among others. In Ecuador, the legal and constitutional entitlement to execute an arbitration agreement for this matter has existed for decades, moreover, its use has been poorly. The reason under our opinion is the lack of its diffusion. In 2019, legal amendments to the Companies Law were announced, which included statutory arbitration. We believe the legislator aimed to promote this mechanism to solve company-related disputes. However, the final approved text deserves to be commented.
\end{abstract}

KEYWORDs: statutory arbitration, corporate disputes, legislative amendments.

\section{INTRODUCCIÓN}

El arbitraje estatutario es aquel "que se constituye mediante la incorporación de una cláusula en el pacto social que establece la solución de los conflictos societarios mediante la utilización del proceso de arbitraje" ${ }^{11}$. El convenio arbitral como parte del estatuto, entonces, i) dependiendo del ámbito derivado de su extensión, de un lado, y ii) de la adhesión de las distintas voluntades en juego, de otro, puede vincular tanto a la sociedad como a sus socios, administradores, fiscalizadores, etc., en todo lo relacionado con derechos transigibles conectados con la actividad social.

Hace poco más de un año, se anunciaban reformas a la Ley de Compañías en el Ecuador y que una de las posibles "innovaciones" se referiría a arbitraje en materia societaria. Advertimos, en su momento, que los cambios legislativos en este campo no siempre pueden resultar necesarios, pues, el arbitraje -al ser esencialmente

1. A. Rojas Chan. "Algunas consideraciones sobre el arbitraje estatutario como mecanismo alterno para la solución de conflictos societarios", Derecho Societario, Concursal y del Consumo, Tomo III, Ed. Jurídica Continental, 2017, p. 3. 
negocial- ya estaba permitido para esta materia ${ }^{2}$. En este sentido, el tratar de reconocer una situación que el ordenamiento jurídico ecuatoriano no prohíbe, sería solamente una añadidura de bulto que, inclusive, podría generar confusiones innecesarias.

Asimismo, pusimos sobre la mesa que la falta de uso del arbitraje -como un mecanismo idóneo para resolver controversias societarias- no se debía a una falta de reconocimiento expreso en la ley. Por el contrario, afirmamos que el problema de fondo era la falta de difusión sobre la habilitación legal existente y la ausencia de publicidad sobre sus beneficios.

Poco después, la Superintendencia de Compañías Valores y Seguros (SCVS) anunció las reformas en esta materia, las cuales -como lo adelantamos- acarreaban "aclaraciones" innecesarias. Creemos en la buena intención del legislador al tratar de incentivar el arbitraje intra-societario. Sin embargo, los textos adoptados no son prolijos. Por el contrario, resultan inoficiosos. Querían niña y salió niño.

Con estos antecedentes en mente, consideramos que para entender por quélas últimas reformas no aportan al objetivo buscado, es fundamental (ii) recapitular el desarrollo del arbitraje estatutario en el Ecuador; (iii) analizar los momentos de incorporación del convenio arbitral en un estatuto social y sus implicaciones; para luego, (iv) estudiar los textos adoptados en las reformas legislativas. Finalmente, (v) expondremos nuestras conclusiones.

\section{Arbitraje societario en ecuador}

\subsection{Habilitación legal del arbitraje estatutario previo a las reformas a la Ley de Compañías}

Previo a la entrada en vigor de la Ley de Arbitraje y Mediación de 1997 (LAM), en Ecuador se encontraba vigente la Ley de Arbitraje

2. Ver, E. Carmigniani y B. Muriel. "Arbitraje Estatutario (societario) en Ecuador", Revista de Derecho Societario, No. 13, Edino, Guayaquil, 2019 y E. CARMIGNIANI, “Arbitraje Societario", El Expreso, 13/02/2020<https://www.expreso.ec/opinion/columnas/eduardo-carmigniani/ arbitraje-societario-5192.html>. 
Comercial dictada por Decreto Supremo 735, del 23 de octubre de 1963. La Ley de Arbitraje Comercial en sus considerandos establecía que su finalidad era la simplificación del manejo de conflictos en operaciones comerciales, siendo el arbitraje una herramienta que cumplía esta finalidad, proporcionando "mayores garantías para esta clase de operaciones y facilitando a los contratantes la solución de litigios, conforme a las actuales exigencias de la actividad comercial" 3 .

Es de fácil comprensión que los conflictos intra-societarios son en esencia de naturaleza comercial. Por consiguiente, se encontraban dentro del ámbito de la Ley de Arbitraje Comercial, pues su artículo 1 se refería precisamente al arbitraje de "controversias comerciales existentes o futuras" ${ }^{\prime 4}$.

Luego, con la entrada en vigor de la LAM en 1997, sin duda, el reconocimiento -en general- del arbitraje se consolidó. A partir de este momento, esta institución ha adquirido especial relevancia para garantizar la agilidad comercial y la resolución de disputas en dicho ámbito. Previo e independientemente del reconocimiento expreso que las nuevas reformas a la Ley de Compañías han realizado sobre el arbitraje estatutario, este ya se encontraba habilitado en el ordenamiento jurídico ecuatoriano. Esto por lo siguiente:

Primero, es incuestionable que para recurrir a arbitraje debe existir un acuerdo entre las partes, con arreglo al artículo 5 de la LAM. Este criterio no difiere en el arbitraje intra-societario (estatutario), pues las potenciales partes en un conflicto de esa naturaleza tienen plena libertad para pactarlo al no existir disposición alguna en contrario.

Segundo, en lo que se refiere a los límites ratione materiae, el artículo 190 de la Constitución "reconoce el arbitraje, la mediación y otros procedimientos alternativos para la solución de conflictos. Estos procedimientos se aplicarán con sujeción a la ley, en materias en las que por su naturaleza se pueda transigir" ${ }^{\prime \prime}$. Por su parte, el artículo 5 de la LAM prevé que para someter una disputa a arbitraje,

3. Ley de Arbitraje Comercial, Considerandos, Decreto Supremo No. 375, RO No. 90, 28/10/1963.

4. Ídem, Artículo 1.

5. Constitución del Ecuador, Artículo 190, R.O. 499, 20/10/2008. 
estas debe ser "susceptible de transacción" 6 . De estas disposiciones es claro que el arbitraje es un mecanismo eficaz para dirimir toda controversia que sea transigible. Entonces, cabe analizar qué debe entenderse por transigibilidad y si las controversias intra-societarias corresponden o no a esta naturaleza.

El artículo 2348 del Código Civil define a la transacción como "un contrato en que las partes terminan extrajudicialmente un litigio pendiente, o precaven un litigio eventual"7. Y el artículo 2349 agrega que "No puede transigir sino la persona capaz de disponer de los objetos comprendidos en la transacción"8. Entonces, la transigibilidad como requisito de arbitrabilidad se refiere a derechos u obligaciones de libre disposición.

Las disputas que pueden surgir en el mundo intra-societario son -generalmente- de dicha naturaleza. Esto es evidente porque tales controversias surgen esencialmente en el ámbito de derecho privado. Así, por ejemplo, los conflictos relacionados con los derechos de voto, información, asistencia, representación, privilegios, etc. o los conflictos relacionados con los deberes y obligaciones de los administradores y directivos de la compañía innegablemente son dispositivos. Es decir, las partes pueden exigirlos, negociar sobre ellos e incluso abstenerse de su ejercicio, pues forman parte de su propiedad privada y de sus intereses individuales.

Para mayor ilustración, exponemos como referencia algunas circunstancias o disputas que podrían manifestarse en el contexto de una relación intra-societaria. Estos ejemplos han sido tomados de la guía sobre conflictos arbitrables que se encuentra en el Informe sobre Arbitraje Societario en España, del Club Español de Arbitraje. Entre ellos se encuentran los siguientes:

-Los conflictos en torno a la constitución de la sociedad (acciones de responsabilidad contra quienes actuaron en nombre de la sociedad antes de su inscripción, responsabilidad de los fundadores, nulidad de la sociedad);

6. Ley de Arbitraje y Mediación, Artículo 5, R.O. No. 145, 04/09/1997.

7. Código Civil, Artículo 2348, R.O. Sup. No. 46, 24/06/2005.

8. Código Civil, Artículo 2348, R.O. Sup. No. 46, 24/06/2005. 
-Los conflictos en torno a las aportaciones dinerarias y no dinerarias y su desembolso, a los dividendos pasivos y a las prestaciones accesorias;

-Las impugnaciones de acuerdos de la junta general y del consejo de administración, incluyendo las aprobaciones de cuentas;

-Los conflictos relacionados con los derechos de los socios (voto, información, asistencia, representación, privilegios);

-La responsabilidad de los administradores (acción social, acción individual);

-Los conflictos y controversias que puedan suscitarse entre socios o con administradores a propósito de la convocatoria de la junta general y del consejo de administración; en estos casos, el conflicto -incluyendo la convocatoria judicial de la junta en los supuestos previstos por la ley- puede ser resuelto mediante arbitraje;

-La impugnación de una fusión u otra operación societaria, siempre que los estatutos de la sociedad absorbente, de la sociedad de nueva creación o de la sociedad supérstite incluyan la sumisión a arbitraje; y

-Los conflictos sobre separación y exclusión de socios, sobre valoración de participaciones o acciones y sobre la transmisión de acciones o participaciones ${ }^{9}$.

Este listado referencial de potenciales conflictos es concordante con los requisitos de arbitrabilidad en razón de la materia previstos en la Constitución y la LAM. Esto, pues responden al ámbito privado de la relación negocial y al ejercicio libre de derechos y obligaciones dispositivos. En definitiva, bajo el ordenamiento jurídico ecuatoriano es posible arbitrar controversias societarias e incluir un convenio arbitral en el estatuto social de cualquier compañía, independientemente de que ahora existiese o no un reconocimiento expreso para ciertas figuras sociales.

9. Informe sobre Arbitraje Societario en España del Club Español de Arbitraje, pp. 40-41. 
Esta conclusión, es importante porque el actual reconocimiento legal expreso del arbitraje estatutario para ciertas figuras sociales en Ecuador i) no excluye su aplicación en otras figuras societarias no reguladas y ii) no deben entenderse como un limitante o restrictivo de derechos, pues no establece prohibición alguna. Entonces, las reformas legales que se analizan en este artículo simplemente constituyen un reconocimiento, digamos, para mayor abundamiento, de lo que en Ecuador ya era permitido.

\subsection{Habilitación DEL ARbitraje Estatutario EN LA PRÁCTICA}

Con la promulgación de la LAM, también se formó una comunidad académica y profesional encaminada a promover y fortalecer el arbitraje como institución. La comunidad arbitral se encuentra en constante campaña para garantizar y fortalecer las cualidades de este sistema y proteger sus características esenciales, como la especialidad, celeridad, flexibilidad, independencia e imparcialidad. No obstante, poco -o nada- se había discutido sobre el arbitraje societario (estatutario) hasta las reformas empezadas a tramitar en el 2019 en el Ecuador.

Así, se ignoraba un ámbito ratione materiae del arbitraje que en otras jurisdicciones era derecho vivo, pues ciertamente responde a las necesidades empresariales contemporáneas. Por ejemplo, en 2011 España reformó su Ley de Arbitraje, incorporando expresamente el arbitraje estatutario para resolver los conflictos que se planteen "en las sociedades de capital"10, aclarando así ciertas dudas que se habían presentado sobre su aplicación ${ }^{11}$. En España, la arbitrabilidad de disputas societarias contaba con gran raigambre, al punto que estaba prevista en el Código de Comercio de 1829 en su artículo 323 como el mecanismo idóneo para su resolución: “toda diferencia entre los socios se decidirá por jueces árbitros, háyase ó no estipulado así en el contrato de sociedad"12.

10. Ley de Arbitraje, Artículo 11 bis 'Arbitraje estatutario', BOE No. 309, 26/12/2003.

11. Informe sobre Arbitraje Societario en España del Club Español de Arbitraje, p. 19.

12. Código de Comercio de España, Artículo 323, 30/05/1829. 
Otro ejemplo es el caso de Chile. El artículo 4(10) de la Ley No. 18.046 dispone que la escritura de constitución de una sociedad anónima debe expresar:

La naturaleza del arbitraje a que deberán ser sometidas las diferencias que ocurran entre los accionistas en su calidad de tales, o entre éstos y la sociedad o sus administradores, sea durante la vigencia de la sociedad o durante su liquidación. Si nada se dijere, se entenderá que las diferencias serán sometidas a la resolución de un árbitro arbitrador ${ }^{13}$.

En su artículo 125 se agrega el texto a continuación, el cual denota que el legislador chileno se decanta por una opción preferencial por el arbitraje para solucionar conflictos intra-societarios:

En los estatutos sociales se establecerá la forma como se designarán el o los árbitros que conocerán las materias a que se refiere el No. 10 del artículo $4^{\circ}$ de la presente ley. En caso alguno podrá nominarse en ellos a una o más personas determinadas como árbitros. El arbitraje que establece esta ley es sin perjuicio de que, al producirse un conflicto, el demandante pueda sustraer su conocimiento de la competencia de los árbitros y someterlo a la decisión de la justicia ordinaria ${ }^{14}$.

Podemos apreciar que en otras jurisdicciones -desde hace tiempo- es común incluir convenios arbitrales en los estatutos de una compañía. Esto responde a los amplios beneficios que el arbitraje ofrece en comparación con el sistema judicial ordinario ${ }^{15}$. Así, este mecanismo es el único suficiente para que los conflictos societarios se resuelvan: i) de manera confidencial, para evitar los impactos negativos que una controversia entre socios, con la sociedad o con la administración puede generar en sus consumidores o clientes; ii) de manera eficiente, diseñando un proceso flexible que se ajuste a las necesidades particulares de cada caso; iii) ante árbitros expertos en temas corporativos y comerciales; y, iv) de manera definitiva, evitando posteriores instancias y reclamaciones que provoquen un retardo excesivo.

13. Ley No. 18-046 Sobre Sociedades Anónimas, Artículo 4(10), Diario Oficial, 22/10/1981.

14. Ídem, Artículo 125.

15. G.Born. International Commercial Arbitration. Second Edition. Kluwer Law, 2014, p.134; pp. 1503-1504. 
Sin embargo, en el Ecuador, estas ventajas pasaron desapercibidas por muchos años, posiblemente como consecuencia de dos claros defectos en nuestro sistema. Primero, por la formación equivocada de un prejuicio que se ha formado respecto de que la materia societaria debe ser altamente regulada, controlada y de (supuesto) orden público, pese a que en verdad es el núcleo del derecho de los negocios. Segundo, por una errada noción de practicantes que tercamente se limitan a las formalidades y a la regulación expresa y, de esta manera, descartan el principio esencial del derecho privado por el cual todo se encuentra permitido, mientras no exista prohibición expresa.

\section{Formas de inCORPORACIÓn DEL ARbITRAJE ESTATUTARIO}

Hemos dicho que la incorporación de un convenio arbitral estatutario responde a la autonomía de la voluntad. Pero hay que diferenciar los distintos momentos en que dicho pacto puede desplegar efectos, pues dependiendo de eso distintos serán tanto sus requisitos como su alcance.

\subsection{Incorporación en la fundación}

Para la Ley de Compañías una compañía mercantil surge de un contrato por el que "dos o más personas unen sus capitales o industrias para emprender en operaciones mercantiles y participar de sus utilidades" ${ }^{\prime 16}$. Si, surgiendo las compañías mercantiles de un contrato, y siendo este el que incorpora el estatuto que regula su funcionamiento, un convenio arbitral estatutario inserto en el acto fundacional contiene la voluntad unánime de los socios fundadores.

Desde esta perspectiva, respecto de los socios fundadores no puede haber duda de que están vinculados al convenio arbitral estatutario, pues expresamente declararon su voluntad en el acto fundacional del que fueron parte. En el estatuto existe, en torno a los socios fundadores, el "acuerdo escrito en virtud del cual las partes deciden someter a arbitraje todas las controversias o ciertas controversias que hayan surgido o puedan surgir entre ellas respecto

16. Ley de Compañías, Artículo 1, R.O. No. 312, 05/11/1999. 
de una determinada relación jurídica"17, exigido por la LAM para que exista convenio arbitral.

Distinto es el caso de los administradores. Como estos no necesariamente forman parte del contrato que da origen a la sociedad, para que queden vinculados a un convenio arbitral estatutario que mande a arbitrar conflictos sociedad-administradores o sociosadministradores, es necesario que se adhieran al convenio arbitral. Para ello, solo basta que estos acepten su designación. Esto es aplicable, mutatis mutandis, a los convenios arbitrales incluidos vía reforma de estatutos, a los que nos referiremos en la sección siguiente.

\subsection{Incorporación posterior a la fundación}

La incorporación de un convenio arbitral en los estatutos luego de constituida la sociedad también es posible por la vía de reforma estatutaria. Pero la reforma abre la discusión sobre si quedan o no vinculados al convenio arbitral los socios ausentes de la sesión de junta general en que se aprobó la reforma, o incluso quienes estando presentes votaron en contra.

Sostenemos que los socios ausentes y los disidentes quedan vinculados por el convenio arbitral incorporado en el estatuto vía reforma. Participar en una sociedad implica aceptar las decisiones sometidas a votación y por ende, los resultados derivados de la mayoría. Como dice Mantilla Serrano, al seguir las reglas contenidas en el estatuto:

Se está aceptando el fenómeno de decisión por la mayoría, si se respetan esas mayorías al realizar una reforma estatutaria que permita incluir un acuerdo de arbitraje, aunque haya votado en contra, el socio minoritario, quedaría vinculado por el pacto arbitral por el mero hecho ser socio ${ }^{18}$.

Esa es la línea que sigue la Ley de Compañías cuando dice que: "Las resoluciones de la junta general son obligatorias para todos

17. Ley de Arbitraje y Mediación, Artículo 5, R.O. No. 145, 04/09/1997.

18. F. Mantilla Serrano. "El Arbitraje en Materia Societaria", p. 31, 16/05/2009, citado en F. CARRASCo FernÁNDEZ. “Arbitraje Societario”, Anuario Jurídico, Instituto de Investigaciones Jurídicas de la UNAM, 2009, p. 358. 
los accionistas, aun cuando no hubieren concurrido a ella, salvo el derecho de oposición en los términos de esta Ley"19.

Respecto del derecho de oposición, el artículo 215 de la Ley de Compañías establece que:

Los accionistas que representen por lo menos la cuarta parte del capital social podrán impugnar, según las normas de esta ley y dentro de los plazos que establece, los acuerdos de las juntas generales o de los organismos de administración que no se hubieren adoptado de conformidad con la ley o el estatuto social, o que lesionen, en beneficio de uno o varios accionistas, los intereses de la compañía ${ }^{20}$.

Como puede observarse, el derecho de impugnación no es abierto, no basta la simple inconformidad de la minoría. Se requiere, para su procedencia, que la decisión respectiva: i) no se hubiere adoptado de conformidad con la ley; o ii) no se hubiere adoptado de conformidad con el estatuto social; o iii) que lesione, en beneficio de uno o varios accionistas, los intereses de la compañía. Consecuentemente, en el caso particular de la inclusión en el estatuto social de un convenio arbitral, se debe hacer hincapié en que de haber sido aprobada la reforma estatutaria siguiendo los procedimientos aplicables (lo que descarta las dos primeras hipótesis de impugnabilidad), difícilmente puede tener éxito, en un análisis abstracto, sostener que incorporar al arbitraje como mecanismo de resolución de disputas intra-societarias cause per se un perjuicio a la sociedad en beneficio de uno o varios socios.

\subsection{Transferencia de acciones}

¿Qué efecto tiene el pacto arbitral estatutario existente respecto de quien recién se incorpora como socio de una compañía comercial? ¿La cesión de posición contractual que como socio hace el tradente al adquirente conlleva la cesión de la posición contractual del tradente frente al convenio arbitral estatutario? Opinamos que sí.

19. Ley de Compañías, Artículo 245, R.O. No. 312, 05/11/1999.

20. Ídem, Artículo 215. 
El contrato de constitución de una compañía comercial, $\mathrm{su}$ estatuto y sus posteriores reformas, son actos sujetos a publicidad registral. La cesión de la posición de socio, lo que implica el traslado de derechos y obligaciones inherentes a esa calidad, que está gobernada por el estatuto de la sociedad, no deja espacio para la duda de que el adquirente queda vinculado, en todos sus aspectos por aquel, incluyendo el convenio arbitral estatutario, de haberlo.

Sostenemos entonces que la declaración de voluntad del adquirente de adherirse al convenio arbitral previamente existente en los estatutos, se manifiesta cuando acepta la calidad de socio, con todos los derechos y obligaciones que le son inherentes precisamente conforme a esos estatutos. Esa manifestación de voluntad cumple además, en el ordenamiento ecuatoriano, con el requisito exigido por el artículo 5 de la LAM de constar por escrito, tanto en la adquisición de participaciones en una compañía de responsabilidad limitada ${ }^{21}$, como en la adquisición de acciones de una compañía anónima ${ }^{22}$.

\section{Como dice Tarrío:}

Una vez inscrito el convenio arbitral estatutario, configurador de la posición de socio, vincula a los socios presentes y a sus sucesores, quienes al adquirir la acción o participación social se han adherido a los instrumentos contractuales que rigen el funcionamiento de la sociedad de la que pretenden formar parte y, si dentro de ellos está una cláusula compromisoria, quedarán vinculados por ella [...] toda novación subjetiva de la posición de socio provoca una subrogación en la del anterior, aunque limitado a las controversias derivadas de la relación societaria ${ }^{23}$.

En resumen, la inclusión de un convenio arbitral para solventar disputas societarias transigibles entre los diferentes agentes que participan en una compañía puede darse en distintos momentos: desde la celebración del acuerdo de los socios o accionistas, y de

21. Ídem, Artículo 113.

22. Ídem, Artículos 188 y 189.

23. M. TARRío Bejarano. "La Cláusula Estatutaria para la Sumisión a Arbitraje de la Impugnación de los Acuerdos Sociales Esquema de Situación”, Consejo General del Notariado, No. 56, 2011, p. 135 . 
manera posterior a través de una reforma. Asimismo, en caso de una transferencia de acciones o participaciones, el cesionario se encuentra también vinculado al convenio arbitral.

\section{REFORMAS RECIENTES}

Siendo claro que la inutilización del arbitraje estatutario en Ecuador ha obedecido a falta de difusión y no a un innecesario "reconocimiento expreso" en la ley, estudiaremos las reformas recientes en esta materia.

\subsection{La primera reforma}

El 28 de febrero de 2020 se promulgó la Ley Orgánica de Emprendimiento e Innovación ${ }^{24}$, que incorporó a las sociedades por acciones simplificadas como una nueva especie societaria (en adelante SAS). La Disposición Reformatoria Octava de dicha ley regula el funcionamiento de las SAS y además incluye de manera expresa la posibilidad de resolver disputas a través de arbitraje (en adelante identificada como la Primera Reforma). A continuación, su texto:

[1]as diferencias que surjan entre los accionistas, la sociedad o losadministradores de una sociedad poracciones simplificada, que tengan relación con la existencia o funcionamiento de la sociedad, incluida la impugnación de determinaciones de asamblea o junta directiva, así como el abuso del derecho, podrán ser resueltas a través de una mediación.

En caso de no llegarse a un acuerdo amistoso, las diferencias mencionadas en el inciso anterior podrán someterse a decisión arbitral, si así se pacta en el estatuto social. En este último caso, al dorso de los títulos de acciones constará una mención de la correspondiente cláusula compromisoria, incorporada al estatuto de la sociedad. Cumplido aquel requerimiento, se entenderá que el cesionario de una transferencia de acciones ha aceptado, de manera expresa, someterse al convenio arbitral previsto en el estatuto social ${ }^{25}$.

24. Ley Orgánica de Emprendimiento e Innovación, R.O. Sup. No. 151, 28/02/2020.

25. Ídem, Disposición Reformatoria Octava a la Sección VIII de la Ley de Compañías, Artículo Innominado. 
De la Primera Reforma podemos destacar los siguientes elementos:

Primero, la norma reconoce que el alcance del convenio arbitral estatutario -ratione personae- puede abarcar controversias entre: i) accionistas; ii) accionistas y la sociedad, iii) accionistas y administradores y iv) sociedad y administradores. Esto es positivo.

Segundo, sobre el objeto de la controversia que puede someterse a arbitraje, la norma se refiere en general a aquellas que tengan relación con la existencia y funcionamiento de la compañía. Esto es también positivo, debiendo entenderse que el listado que agrega ${ }^{26}$ es ejemplificativo y no limitativo.

Tercero, del texto parecería que el arbitraje estatutario debía seguir un proceso escalonado de resolución de disputas. Así, el artículo disponía que: "[e]n caso de no llegarse a un acuerdo amistoso, las diferencias mencionadas en el inciso anterior podrán someterse a decisión arbitral, si así se pacta en el estatuto social". Consideramos que tal entendimiento era equivocado, pues estaba llamado a generar demoras innecesarias. Como se ha expresado, la posibilidad de pactar arbitraje en el estatuto social deviene del principio de libertad contractual.

De hecho, la propia reforma lo confirma al prescribir: "si así se pacta en el estatuto social". Entonces, no es que el arbitraje es admisible por el reconocimiento expreso dado en la Primera Reforma, sino por los principios generales y normas que garantizan el ejercicio libre de las relaciones negociales. Por este motivo, es posible someterse a arbitraje estatutario sin tener que agotar la etapa previa de mediación obligatoria que prevé la Primera Reforma. Esto, considerando además que el propio proceso de arbitraje previsto en la LAM ya contiene una mediación intraprocesal ${ }^{27}$. En síntesis, la referencia a una resolución amistosa o mediación previa es un derecho/obligación de la naturaleza (no de la esencia). Por lo tanto, se puede disponer en forma distinta en el estatuto social. Vale

26. "Incluida la impugnación de determinaciones de asamblea o junta directiva, así como el abuso del derecho".

27. "Una vez contestada o no la demanda o la reconvención, el director del centro de arbitraje o el árbitro o árbitros independientes notificarán a las partes, señalando día y hora para que tenga lugar la audiencia de mediación a fin de procurar un avenimiento de las partes", Ley de Arbitraje y Mediación, Artículo15, R.O. No. 145, 04/09/1997. 
decir que esta disposición fue corregida, actualmente se encuentra eliminada con una reforma que se analizará más adelante.

Cuarto, la inclusión de un convenio arbitral estatutario genera debate sobre qué sucede en caso de una transferencia o cesión de acciones a un tercero, considerando que el nuevo accionista no fue parte, no suscribió, ni consintió en el convenio arbitral que consta en el estatuto. La respuesta a este escenario es intuitiva. Al adquirir la calidad de accionista, y por ende los derechos y obligaciones que como tal surgen del estatuto que contiene una cláusula arbitral, el que era tercero ajeno a la relación social se convierte en parte contractual y por ello se encuentra vinculado al convenio arbitral, $\sin$ que se requiera la firma de otro documento particular. En efecto, y como ya mencionamos:

[1]a voluntad de las partes de someterse a arbitraje aunque no hayan participado en la redacción de los mismos [estatutos], deriva de la propia condición de socio, con subrogación en la posición del anterior, quedando vinculadas como, se han dicho, por el contenido de los estatutos sociales, lo que no significa que no se respete la autonomía de la voluntad de las mismas, que podrán modificar posteriormente los Estatutos Sociales ${ }^{28}$.

La Primera Reforma trajo una inconveniente solución distinta. Así, dispuso que para que un cesionario de acciones se encuentre vinculado al arbitraje previsto en el estatuto, los títulos de acciones deberán contener una mención específica sobre la existencia del convenio arbitral. Solo así se entendería su aceptación. Esta disposición establece un requisito adicional conceptualmente innecesario, que parte de la premisa de que la escrituración del convenio en el estatuto y la publicidad de este negocio jurídico en el Registro Mercantil serían insuficientes. Sobra decir que discrepamos con tal entendimiento. Este error legislativo tuvo que ser corregido, y esta disposición también fue eliminada con una reforma posterior, que se analizará más adelante.

28. M. SÁnchez Pons. La Cláusula Arbitral Estatutaria: Breves apuntes sobre su validez y eficacia, Tratado de Derecho Arbitral, El Convenio Arbitral, Tomo II, Universidad Javeriana e Instituto Peruano de Arbitraje, 2011, p. 183. 
Además de las observaciones de fondo que hemos planteado sobre la Primera Reforma, el principal problema con dicho reconocimiento expreso es que se encuentra limitado a las SAS. Esto, en lugar de promover el arbitraje estatutario, generó dudas y creativas tesis, que sostenían que la posibilidad de arbitrar disputas intra-societarias en otras especies de compañías no sería permitido a falta de similar reconocimiento expreso, nuevo síntoma de la paranoia de invadir áreas del derecho privado con supuestos lineamientos y limitaciones de orden público.

\subsection{La segunda reforma}

Para tratar de resolver las dudas que generó la Primera Reforma, en la Ley de Modernización a la Ley de Compañías de diciembre de $2020^{29}$, se incluyó nuevos reconocimientos expresos sobre la validez de incluir convenios arbitrales, esta vez en los estatutos sociales de las compañías limitadas (artículo 137.2) y las compañías anónimas (artículo 146.1). Veamos los textos:

Artículo 137.2: El estatuto social podrá incluir una cláusula compromisoria como un mecanismo para resolver desacuerdos entre los miembros de la sociedad, siempre que el conflicto recayere sobre materia transigible. En tal caso, procederán los mecanismos alternativos de solución de conflictos en derecho, conforme a las condiciones establecidas en la Ley y lo convenido por las partes.

Si no se hubiere pactado arbitraje para la resolución de conflictos societarios, o si la controversia versare sobre materia no transigible, la competencia para su resolución recaerá sobre el Juez de lo Civil del domicilio principal de la compañía de responsabilidad limitada [o anónima].

De efectuarse una cesión de participaciones, el cesionario quedará sujeto a la cláusula compromisoria prevista en el estatuto social, salvo pacto expreso en contrario.

Artículo 146.1: El estatuto social podrá incluir una cláusula compromisoria como un mecanismo para resolver desacuerdos entre los miembros de la sociedad, siempre que

29. Ley de Modernización a la Ley de Compañías, R.O. Sup. No. 347 de 10/12/2020. 
el conflicto recayere sobre materia transigible. En tal caso, procederá el arbitraje en derecho, conforme a las condiciones establecidas en la Ley y en el convenio arbitral.

Si no se hubiere pactado arbitraje para la resolución de conflictos societarios, o si la controversia versare sobre materia no transigible, la competencia para su resolución recaerá sobre el Juez de lo Civil del domicilio principal de la sociedad anónima.

De efectuarse una transferencia de acciones, el cesionario quedará sujeto a la cláusula compromisoria prevista en el estatuto social, salvo pacto expreso en contrario ${ }^{30}$.

Las diferencias entre estas disposiciones son mínimas. Por un lado, el artículo 137(2) se refiere a compañías limitadas y establece -de manera general- la posibilidad de someterse a mecanismos alternativos de resolución de disputas. Por otro lado, el artículo 146(1) es aplicable a las compañías anónimas y en su primer inciso dispone específicamente la posibilidad de someterse a arbitraje. No obstante, para objeto del análisis de fondo, trataremos a las dos normas como la "Segunda Reforma", pues -en esencia- su contenido es el mismo.

Primero, el texto de la Segunda Reforma parece intentar limitar su aplicación a controversias entre los miembros de la sociedad. Es decir, entre los socios o accionistas, excluyendo las disputas: i) entre socios y sociedad; ii) entre socios $y$ administradores; o iii) entre sociedad y administradores. Esto, no obstante que la Primera Reforma, de pocos meses antes, aplicable a las SAS, es mucho más amplia: "[1]as diferencias que surjan entre los accionistas, la sociedad o los administradores de una sociedad por acciones simplificada, que tengan relación con la existencia o funcionamiento de la sociedad". Es inexplicable este giro restrictivo, que abre espacio a innecesarias discusiones sobre arbitrabilidad.

Segundo, la Segunda Reforma pretende imponer que el arbitraje solo pueda resolverse en derecho, eliminando al arbitraje en equidad como alternativa. No encontramos lógica o motivo alguno para esta restricción, que constituye una inconstitucional intromisión

30. Ídem, Artículos 137.2, 146.1. 
en la libertad negocial. Además es inconveniente. El arbitraje en equidad puede ser en ciertas circunstancias atractivo para dirimir conflictos mercantiles por la necesidad de una resolución apegada a la evolución y requerimientos particulares de cada actividad de comercio.

Tercero, la Segunda Reforma corrige el error de la primera respecto del requisito de incluir al dorso de los títulos de acciones la mención de la cláusula compromisoria estatutaria para vincular a un cesionario. El nuevo texto reconoce el principio de que los nuevos accionistas se vinculan a todas las disposiciones del estatuto -incluyendo el convenio arbitral- con la simple aceptación de la cesión de acciones y debido a la publicidad del estatuto.

No obstante, establece una absurda salvedad: el cesionario nuevo socio o accionista- puede desvincularse del convenio arbitral si existe "pacto expreso". Dado que la adquisición de participaciones o acciones no implica pacto del adquirente con la compañía sino con el tradente, ese tal "pacto expreso" solo pudiera ser con este último. Esa posibilidad de desvinculación unilateral del estatuto (del nuevo socio o accionista) abre un peligrosísimo boquete, que quiebra el principio de que todos los socios o accionistas, por el hecho de serlo, están vinculados a aquel.

Cuarto, la Segunda Reforma no incluye el procedimiento escalonado de resolución de disputas previsto en la Primera Reforma para las SAS. Esto es acertado porque -como lo mencionamosun procedimiento escalonado no es un requisito de la esencia del arbitraje y de hecho en nuestro sistema -que ya contempla una mediación intraprocesal- resulta innecesario.

\subsection{La Tercera Reforma}

Finalmente, la Ley de Modernización a la Ley de Compañías de diciembre de 2020, además de reconocer expresamente el arbitraje para otras especies sociales, reformó la ya existente para las SAS. El texto actual es el siguiente:

Las diferencias que surjan entre los accionistas de una sociedad por acciones simplificada, entre estos y la compañía 
o sus administradores, o entre la sociedad con las personas que la administraren, podrán ser resueltas a través de una mediación. Estas diferencias deberán tener relación con la existencia o funcionamiento de la sociedad por acciones simplificada, incluida la impugnación de determinaciones de la asamblea o Directorio, así como el abuso del derecho.

Las diferencias mencionadas en el inciso anterior también podrán someterse a decisión arbitral, si así se pacta en el estatuto social. De efectuarse una transferencia de acciones, el cesionario quedará sujeto a la cláusula arbitral prevista en el estatuto social, salvo pacto expreso en contrario.

$[\ldots]$

Se deberá incluir a la cláusula arbitral al momento de extender un nombramiento a favor de los administradores de la sociedad por acciones simplificada. De aceptar el nombramiento bajo dichas condiciones, los administradores quedarán sujetos a la cláusula arbitral. Caso contrario, estos no quedarán obligados por el convenio.

En caso de conflictos intrasocietarios, el levantamiento del velo societario también podrá ser ordenado por un tribunal arbitral, de así determinarlo el estatuto social ${ }^{31}$.

Esta, a la que denominaremos "Tercera Reforma" trata de corregir algunos de los errores que ya hemos destacado. No obstante, sigue la misma línea restrictiva, imponiendo requisitos o formalidades innecesarias.

Primero, la Tercera Reforma corrige -específicamente para el caso de las SAS- el error de la primera respecto del requisito de incluir al dorso de los títulos de acciones la mención de la cláusula compromisoria estatutaria para vincular a un cesionario, con la misma desatinada salvedad de la Segunda Reforma.

Segundo, elimina el procedimiento escalonado de resolución de disputas previsto en la Primera Reforma, lo cual, ya hemos dicho, es acertado.

31. Ley de Modernización a la Ley de Compañías, Artículos 68, 69, R.O. Suplemento No. 347, 10/12/2020. Énfasis añadido. 
Tercero, establece una nueva restricción a los conflictos entre: i) sociedad-administradores; y, ii) accionistas-administradores. La Tercera Reforma exige que, para vincular a los administradores de las compañías con el convenio arbitral, su nombramiento incluya una réplica de este. Un error de bulto.

Nuevamente, los derechos y obligaciones -previstos en el convenio arbitral estatutario- surgen de: i) la propia existencia de dicho instrumento social; ii) su aceptación integral; y, iii) la publicidad de su contenido. En síntesis, toda persona que se vincule a la compañía y que mantenga derechos y obligaciones previstos en el estatuto, está vinculada al mecanismo de resolución de controversias previsto en dicho instrumento. No se requiere una ratificación posterior de su voluntad. Este nuevo requisito es contrario a la libertad negocial y entorpece el carácter normativo del estatuto para los administradores ${ }^{32}$. Sin duda, esta disposición generará confusiones sobre su aplicación, una serie de controversias sobre su alcance e incluso, decisiones contradictorias -en sede judicial y arbitral-. Lo que abunda, sí daña.

Cuarto, la Tercera Reforma dispone que podrán resolverse disputas relacionadas con el levantamiento del velo societario en arbitraje. Sin embargo, esta alternativa debe constar expresamente en el estatuto social. Una vez más, el legislador se entromete en una decisión exclusiva de los árbitros respecto de su competencia en razón de la materia. Además, lo hace de manera arbitraria y descuidada. Como mencionamos, una disputa es arbitrable si la materia de la litis es transigible, no por reconocimiento del legislador.

\section{CONCLUSIONES}

Sigue pendiente el trabajo de promover el arbitraje estatutario en Ecuador, quizá con más desafíos que antes de su incorporación expresa en la legislación. Esto debido a las claras ventajas que ofrece este mecanismo en comparación con la justicia ordinaria -eficiencia, flexibilidad, confidencialidad y experticia de los árbitros-. Su fundamento esencial es el principio de autonomía de

32. Si se requiere una ratificación de la voluntad del convenio arbitral del estatuto para vincular a los administradores, por qué no se requeriría de otra obligación prevista en dicho instrumento social. Esta es una duda que la reforma genera innecesariamente. 
la voluntad y su reconocimiento constitucional -artículo 190 de la Constitución-. Las disputas intra-societarias son -en general- de naturaleza transigible, pues responden a intereses privados. Por lo tanto, salvo que se trate de cuestiones no transigibles, ninguna ley puede limitarlo.

Las últimas reformas a la Ley de Compañías, si bien reconocen de manera expresa al arbitraje estatutario, lo hacen de manera incorrecta. Lo que abunda sí daña porque, al menos, causa confusión.

Aspiramos que lo expuesto sirva para continuar el proceso de promoción del arbitraje como el mecanismo idóneo para resolver controversias intra-societarias y para aclarar las dudas o trabas que las "innovadoras" reformas traen en esta materia. 
